medRxiv preprint doi: https://doi.org/10.1101/2021.01.19.21250079; this version posted January $20,2021$. The copyright holder for this preprint (which was not certified by peer review) is the author/funder, who has granted medRxiv a license to display the preprint in It is made available under a CC-BY-NC-ND 4.0 International license.

\title{
Head-to-head comparison of direct-input RT-PCR and RT-LAMP against RT- qPCR on extracted RNA for rapid SARS-CoV-2 diagnostics
}

\author{
Max J. Kellner 1,2\#*, Martin Matl1,2\#, James J. Ross ${ }^{2,3}$, Jakob Schnabl2,3, Dominik \\ Handler $^{2}$, Robert Heinen ${ }^{1,2}$, Justine Schaeffer ${ }^{4,5}$, Peter Hufnagl ${ }^{4}$, Alexander Indra ${ }^{4}$, \\ Marcus P.S. Dekens ${ }^{1}$, Robert Fritsche-Polanz ${ }^{6}$, Manuela Födinger6,7, Johannes \\ Zuber ${ }^{1,8}$, Vienna Covid-19 Detection Initiative (VCDI), Franz Allerberger ${ }^{4}$, \\ Andrea Pauli ${ }^{*} \&$ Julius Brennecke ${ }^{2 *}$
}

1 Research Institute of Molecular Pathology (IMP), Vienna BioCenter (VBC), Campus-ViennaBiocenter 1, 1030 Vienna, Austria.

2 Institute of Molecular Biotechnology of the Austrian Academy of Sciences (IMBA), Vienna BioCenter (VBC), Dr. Bohr-Gasse 3, 1030 Vienna, Austria.

3 Vienna BioCenter PhD Program, Doctoral School of the University at Vienna and Medical University of Vienna, Vienna, Austria.

4 Institute for Medical Microbiology and Hygiene, Austrian Agency for Health and Food Safety, Währingerstr. 25A, 1090 Vienna, Austria.

5 European Centre for Disease Prevention and Control (ECDC), Stockholm, Sweden.

6 Institute of Laboratory Diagnostics, Klinik Favoriten, 1100 Vienna, Austria.

7 Sigmund Freud Private University, 1020 Vienna, Austria.

8 Medical University of Vienna, Vienna BioCenter (VBC), 1030 Vienna, Austria.

\# equal contribution

* corresponding authors

Correspondence should be addressed to:

max.kellner@imp.ac.at, andrea.pauli@imp.ac.at, julius.brennecke@imba.oeaw.ac.at 
medRxiv preprint doi: https://doi.org/10.1101/2021.01.19.21250079; this version posted January 20, 2021. The copyright holder for this preprint (which was not certified by peer review) is the author/funder, who has granted medRxiv a license to display the preprint in It is made available under a CC-BY-NC-ND 4.0 International license .

\section{Vienna Covid-19 Detection Initiative (VCDI) author list:}

Stefan Ameres2 ${ }^{2}$ Benedikt Bauer ${ }^{1}$, Nikolaus Beer ${ }^{1,2,9}$, Katharina Bergauer ${ }^{1}$, Wolfgang Binder ${ }^{10}$, Claudia Blaukopf ${ }^{2}$, Boril Bochev ${ }^{1,2,9}$, Julius Brennecke ${ }^{2}$, Selina Brinnich ${ }^{11}$, Aleksandra Bundalo ${ }^{1}$, Meinrad Busslinger ${ }^{1,8}$, Aleksandr Bykov ${ }^{1}$, Tim Clausen ${ }^{1,8}$, Luisa Cochella ${ }^{1}$, Geert de Vries ${ }^{2}$, Marcus Dekens $^{1}$, David Drechsel ${ }^{1}$, Zuzana Dzupinkova1,2,9, Michaela Eckmann-Mader ${ }^{11}$, Ulrich Elling2, Michaela Fellner ${ }^{1}$, Thomas Fellner ${ }^{11}$, Laura Fin ${ }^{1}$, Bianca Valeria Gapp ${ }^{2}$, Gerlinde Grabmann ${ }^{11}$, Irina Grishkovskaya1, Astrid Hagelkruys ${ }^{2}$, Bence Hajdusits ${ }^{1}$, Dominik Handler ${ }^{2}$, David Haselbach ${ }^{1}$, Robert Heinen ${ }^{1,2,9}$, Louisa Hill1', David Hoffmann², Stefanie Horer1, Harald Isemann'1, Robert Kalis $^{1}$, Max Kellner ${ }^{1,2}$, Juliane Kley ${ }^{1}$, Thomas Köcher ${ }^{11}$, Alwin Köhler ${ }^{10}$, Darja Kordic ${ }^{1}$, Christian Krauditsch ${ }^{2}$, Sabina Kula1,2,9, Richard Latham ${ }^{1}$, Marie-Christin Leitner ${ }^{2}$, Thomas Leonard ${ }^{10}$, Dominik Lindenhofer ${ }^{2}$, Raphael Arthur Manzenreither ${ }^{2}$, Martin Matl ${ }^{1,2}$, Karl Mechtler ${ }^{1,2,9}$, Anton Meinhart ${ }^{1}$, Stefan Mereiter ${ }^{2}$, Thomas Micheler ${ }^{11}$, Paul Moeseneder ${ }^{2}$, Tobias Neumann${ }^{1}$, Simon Nimpf $^{1}$, Magnus Nordborg9 9 , Egon Ogris ${ }^{10}$, Michaela Pagani ${ }^{1}$, Andrea Pauli ${ }^{1}$, Jan-Michael Peters ${ }^{1,8}$, Petra Pjevac ${ }^{12,13}$, Clemens Plaschka1, Martina Rath ${ }^{1}$, Daniel Reumann ${ }^{2}$, Sarah Rieser1, Marianne Rocha-Hasler ${ }^{12}$, Alan Rodriguez ${ }^{1,2}$, James Julian Ross ${ }^{2}$, Harald Scheuch ${ }^{1,2,9}$, Karina Schindler ${ }^{1}$, Clara Schmidt ${ }^{2}$, Hannes Schmidt ${ }^{12}$, Jakob Schnabl ${ }^{2}$, Stefan Schüchner ${ }^{10}$, Tanja Schwickert ${ }^{1}$, Andreas Sommer11, Johannes Stadlmann ${ }^{14}$, Alexander Stark ${ }^{1,8}$, Peter Steinlein ${ }^{1,2,9}$, Simon Strobl11, Qiong Sun ${ }^{1}$, Wen Tang1, Linda Trübestein ${ }^{10}$, Johanna Trupke11, Christian Umkehrer ${ }^{1}$, Sandor Urmosi-Incze $^{11}$, Kristina Uzunova ${ }^{1,2,9}$, Gijs Versteeg15, Alexander Vogt ${ }^{11}$, Vivien Vogt ${ }^{1}$, Michael Wagner $^{12,13}$, Martina Weissenboeck ${ }^{1}$, Barbara Werner ${ }^{11}$, Ramesh Yelagandula ${ }^{2}$, Johannes Zuber ${ }^{1,8}$

1 Research Institute of Molecular Pathology (IMP), Vienna BioCenter (VBC), Campus-ViennaBiocenter 1, 1030 Vienna, Austria.

2 Institute of Molecular Biotechnology of the Austrian Academy of Sciences (IMBA), Vienna BioCenter (VBC), Dr. Bohr-Gasse 3, 1030 Vienna, Austria.

3 Vienna BioCenter PhD Program, Doctoral School of the University at Vienna and Medical University of Vienna, Vienna, Austria.

4 Institute for Medical Microbiology and Hygiene, Austrian Agency for Health and Food Safety, Währingerstr. 25A, 1090 Vienna, Austria.

5 European Centre for Disease Prevention and Control (ECDC), Stockholm, Sweden.

6 Institute of Laboratory Diagnostics, Klinik Favoriten, 1100 Vienna, Austria.

7 Sigmund Freud Private University, 1020 Vienna, Austria.

8 Medical University of Vienna, Vienna BioCenter (VBC), 1030 Vienna, Austria.

9 Gregor Mendel Institute (GMI), Austrian Academy of Sciences, Vienna Biocenter (VBC), Dr. Bohr-Gasse 3, 1030 Vienna, Austria.

10 Max Perutz Labs, Medical University of Vienna, Vienna Biocenter (VBC), Dr. Bohr-Gasse 9/3, 1030 Vienna, Austria.

11 Vienna Biocenter Core Facilities GmbH (VBCF), Dr. Bohr-Gasse 3, 1030 Vienna, Austria.

12 Centre for Microbiology and Environmental Systems Science, University of Vienna, Althanstrasse 14, 1090 Vienna, Austria.

13 Joint Microbiome Facility of the University of Vienna and Medical University of Vienna, Althanstrasse 14, 1090 Vienna, Austria.

14 Institute of Biochemistry, University of Natural Resources and Life Sciences (BOKU), Muthgasse 18, 1190 Vienna, Austria.

15 Department of Microbiology, Immunobiology, and Genetics, Max Perutz Labs, University of Vienna, Vienna Biocenter (VBC), Dr. Bohr-Gasse 9, 1030 Vienna, Austria. 
medRxiv preprint doi: https://doi.org/10.1101/2021.01.19.21250079; this version posted January 20, 2021. The copyright holder for this preprint (which was not certified by peer review) is the author/funder, who has granted medRxiv a license to display the preprint in

It is made available under a CC-BY-NC-ND 4.0 International license.

\section{SUMMARY}

Viral pandemics, such as Covid-19, pose serious threats to human societies. To control the spread of highly contagious viruses such as SARS-CoV-2, effective test-trace-isolate strategies require population-wide, systematic testing. Currently, RT-qPCR on extracted RNA is the only broadly accepted test for SARS-CoV-2 diagnostics, which bears the risk of supply chain bottlenecks, often exaggerated by dependencies on proprietary reagents. Here, we directly compare the performance of gold standard diagnostic RT-qPCR on extracted RNA to direct input RT-PCR, RT-LAMP and bead-LAMP on 384 primary patient samples collected from individuals with suspected Covid-19 infection. With a simple five minute crude sample inactivation step and one hour of total reaction time, we achieve assay sensitivities of $98 \%$ (direct RT-PCR), 93\% (bead-LAMP) and $82 \%$ (RTLAMP) for clinically relevant samples (diagnostic RT-qPCR Ct $<35$ ) and a specificity of $>98 \%$. For direct RT-PCR, our data further demonstrate a perfect agreement between real-time and end-point measurements, which allow a simple binary classification similar to the powerful visual readout of colorimetric LAMP assays. Our study provides highly sensitive and specific, easy to implement, rapid and cost-effective alternatives to diagnostic RT-qPCR tests.

Keywords: Covid-19 diagnostics, RT-LAMP, RT-PCR, Coronavirus, SARS-CoV-2

\section{RESULTS \& DISCUSSION}

We obtained 384 primary patient samples to benchmark, in parallel, three laboratory-developed SARS-CoV-2 tests [1] against a diagnostic RTqPCR assay, which uses extracted RNA as input [2] (Figure 1A). 271 samples were nasooropharyngeal swabs in viral transport medium (VTM) or $0.9 \% \mathrm{NaCl}$ solution (saline), and 113 were gargle samples in saline or Hank's Balanced Salt Solution (HBSS). For all samples, we quantitatively determined SARS-CoV-2 levels via the gold-standard RT-qPCR (E-gene) on extracted RNA in the diagnostic laboratory of the Austrian Agency for Health and Food Safety (AGES), the Austrian national public health agency. This confirmed SARS-CoV-2 virus in 161/384 samples (102 swabs and 59 gargle specimens) with viral titres ranging between 0.2 and 100 million copies per microliter primary sample (Supplementary Figure S1A). Each of the three rapid assays described below direct RT-PCR, RT-LAMP, beadLAMP bypasses the time-consuming and costly RNA extraction step. Instead, we used a fiveminute inactivation procedure of the primary sample in QuickExtract (Lucigen) buffer, which effectively lyses virions and permanently inactivates RNases, thereby generating a noninfectious sample with stable viral RNA [3]. This method is compatible with naso-oropharyngeal swabs, sputum, saliva and gargle $[1,4]$.

\section{Direct RT-PCR}

The direct RT-qPCR method is analogous to diagnostic RT-qPCR assays but circumvents the dedicated RNA extraction step and uses inexpensive, readily available reagents [3,5]. We performed direct RT-qPCR using Luna One-Step RT-qPCR reagents (New England Biolabs) and the CDC N1 SARS-CoV-2 reference primer/probe set (IDT) [1]. The obtained Ct-values correlated strongly with the diagnostic RT-qPCR values (Spearman correlation Rho $=0.93$ ), demonstrating that omitting the RNA extraction step does not distort quantitative measurements and that RTPCR-inhibiting substances are not prevalent in naso-oropharyngeal swab and gargle samples (Figure 1B). On average, Ct values of the direct RT-PCR assay were $\sim 2$ cycles higher compared to the diagnostic $\mathrm{Ct}$-values. This indicated minor losses in sensitivity (Figure 1B), which we attribute to the lower input amount per reaction in direct RT-PCR (no RNA extraction and enrichment compared to the diagnostic RT-qPCR). With the exception of two outliers ( $\mathrm{Ct} 28$ and $\mathrm{Ct} 29$ ), all samples with a diagnostic RT-qPCR $\mathrm{Ct}$ value below or equal to 35 (more than $\sim 30$ viral copies per reaction; $\mathrm{n}=104$ samples) as well as 35 out of 55 samples with clinical $\mathrm{Ct}$ values above 35 $(63.3 \%)$ were positive by direct RT-qPCR (Figure $1 \mathrm{~B}, \mathrm{H})$. Thus, specimens yielding false negative results by the direct RT-qPCR method had very low viral copy numbers (Figure 1B, H). Among the 
medRxiv preprint doi: https://doi.org/10.1101/2021.01.19.21250079; this version posted January 20, 2021. The copyright holder for this preprint (which was not certified by peer review) is the author/funder, who has granted medRxiv a license to display the preprint in It is made available under a CC-BY-NC-ND 4.0 International license .

\section{Figure 1}

A

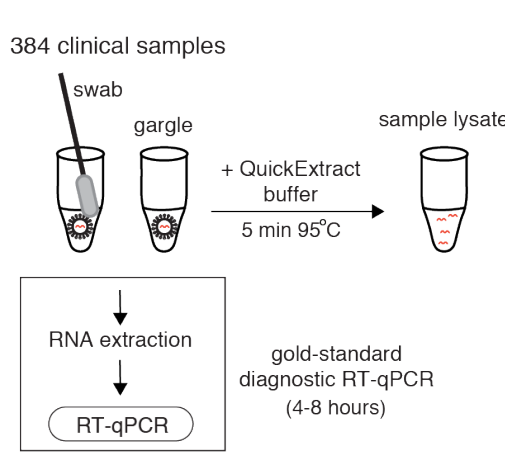

C

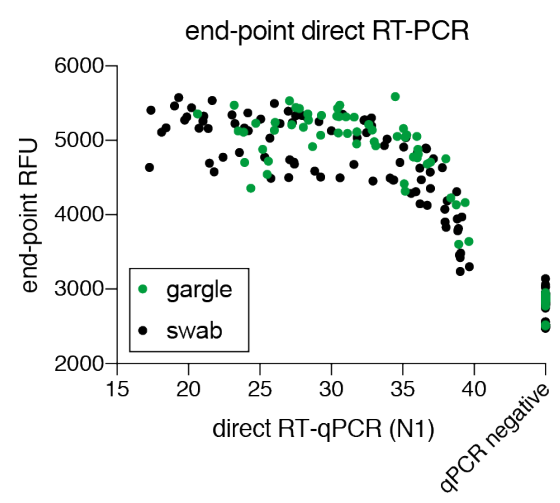

$\mathbf{F}$

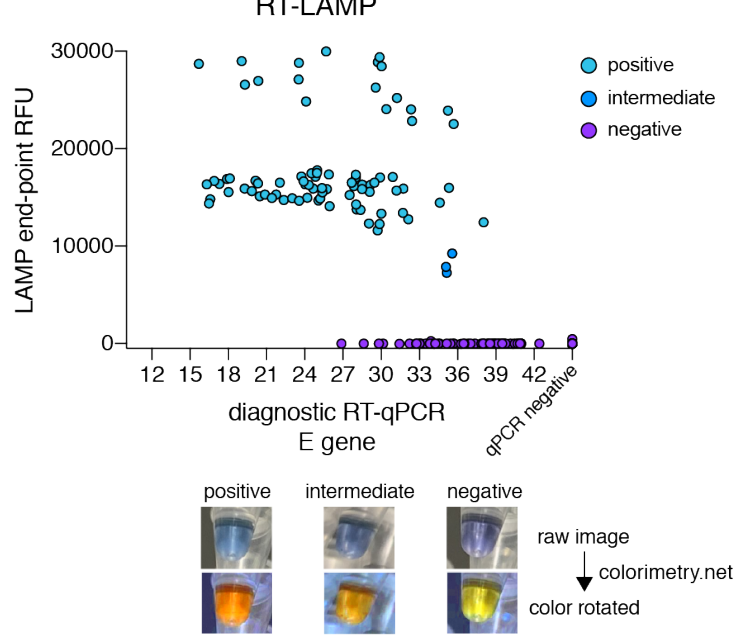

H
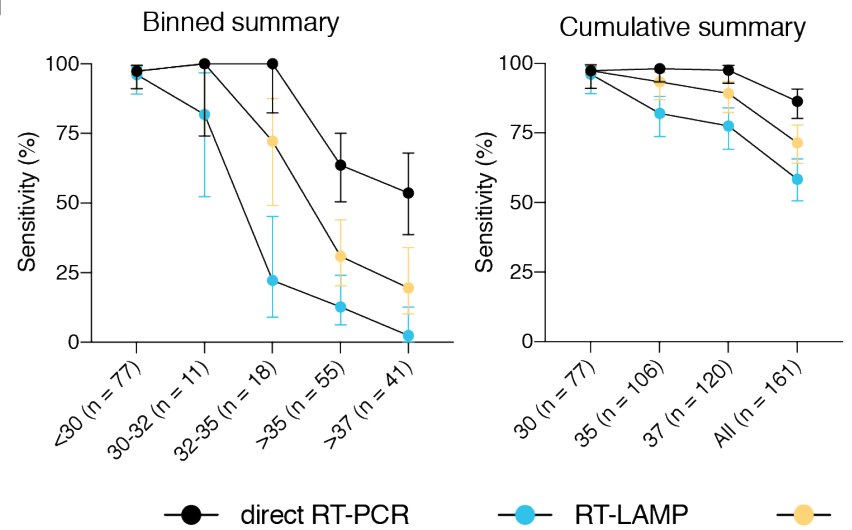

-c- RT-LAMP
B

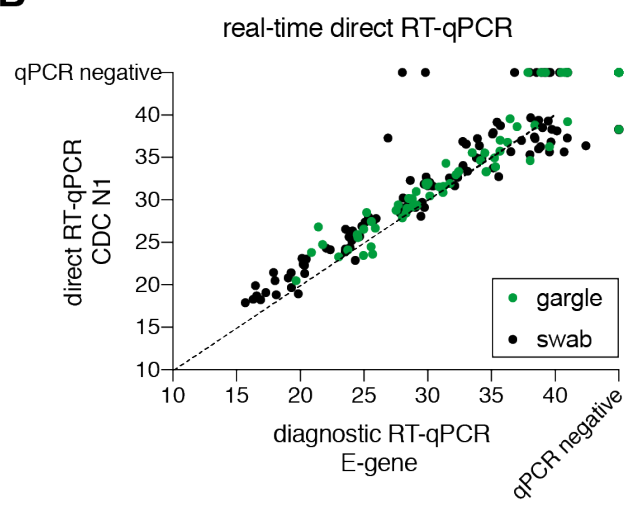

E

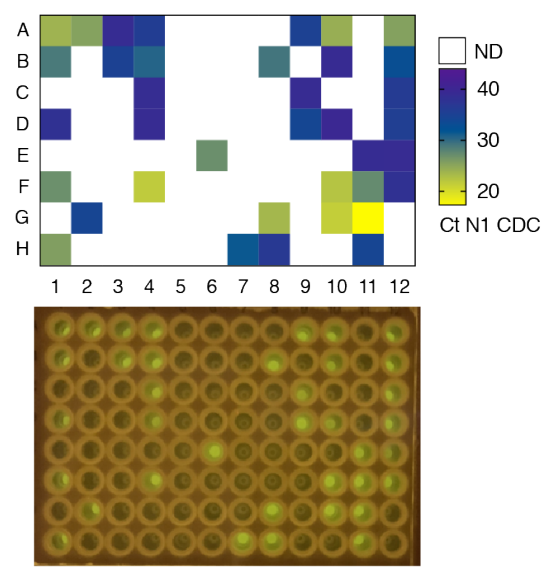

G

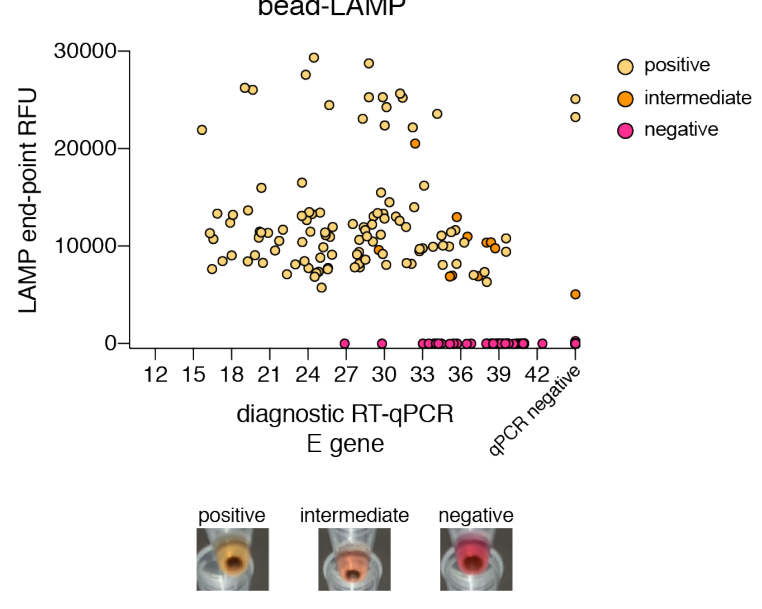

I

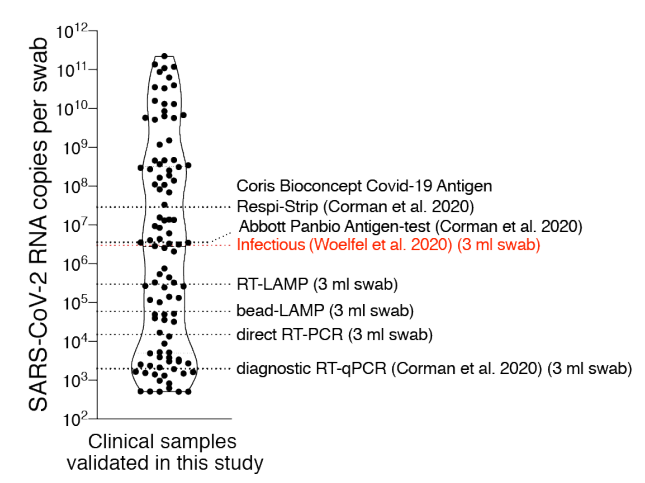


medRxiv preprint doi: https://doi.org/10.1101/2021.01.19.21250079; this version posted January 20, 2021. The copyright holder for this preprint (which was not certified by peer review) is the author/funder, who has granted medRxiv a license to display the preprint in

It is made available under a CC-BY-NC-ND 4.0 International license .

\section{Figure 1: Head-to-head comparison of direct-input RT-PCR and RT-LAMP assays against diagnostic RT-qPCR}

A. Schematic illustrating the workflow for the head-to-head comparison of three rapid, laboratorydeveloped tests (direct RT-PCR, RT-LAMP, bead-LAMP) against diagnostic RT-qPCR for rapid SARSCoV-2 diagnostics. A five-minute heat-inactivation step in QuickExtract buffer circumvents the RNA extraction of the gold-standard diagnostic RT-qPCR protocol.

B. Comparison of real-time direct RT-qPCR to diagnostic RT-qPCR. Each dot represents the Ct (cycle threshold) value of an individual sample measured by the two techniques. The color indicates the sample type (naso/oropharyngeal swab or gargle). The dashed line indicates a $100 \%$ theoretical agreement. Spearman's correlation coefficient (Rho) was calculated for the correlation analysis between diagnostic RT-qPCR and direct RT-qPCR.

C. Comparison of real-time direct RT-qPCR and end-point direct RT-PCR. Each dot represents the $\mathrm{Ct}$ value of an individual sample and its corresponding end-point relative fluorescence units (RFU) measured from the same reaction. Sample type is indicated by the color of the data-point (naso/ oropharyngeal swab or gargle).

D. Data shown in C) split up into groups by diagnostic RT-qPCR Ct values. Mann-Whitney test was used to compare end-point RFUs within individual groups to the values measured for RT-qPCR negative samples $(* * * *<0.0001$ significance).

E. Heatmap showing measured direct RT-qPCR Ct values for a 96-well sample plate (top) and the corresponding end-point fluorescence smartphone image taken on a standard LED blue-light transilluminator (bottom).

F. Comparison of RT-LAMP to diagnostic RT-qPCR. Each dot represents the Ct value of an individual sample and its corresponding end-point RFU values measured by RT-LAMP reactions containing HNB and the fluorescent SYTO-9 dye. The color of each data point indicates the final reaction color obtained by RT-LAMP. Representative examples of final reaction colors (raw images) and the corresponding color-rotated images (colorimetry.net), which facilitate scoring of the color changes, are shown underneath.

G. Same as shown in F) but for Kingfisher bead-LAMP using $60 \mu 1$ of lysate as input.

H. Determined assay sensitivity and specificity of direct RT-PCR (black), RT-LAMP (blue) and beadLAMP (yellow) in comparison to diagnostic RT-qPCR performed on the same 384 samples. The binned (left) and cumulative (middle) sensitivity graphs show the mean detection rate with error bars representing the $95 \%$ confidence interval (Wilson/Brown binomial confidence interval). The assay specificity graph (right) shows the percentages of negative agreement between each of the alternative tests with the diagnostic RT-qPCR.

I. Overview of different SARS-CoV-2 detection assays and their respective limits of detection. The SARS-CoV-2 RNA concentration for each clinical naso/oro-pharyngeal swab sample was calculated from diagnostic RT-qPCR Ct values and plotted $(\log 10)$. Dotted lines indicate the limit of detection (95\% confidence interval) for various assays measured in this study (RT-LAMP, bead-LAMP, direct RT-PCR) or elsewhere (Abbott Panbio Antigen-test and Coris Bioconcept Covid-19 Antigen RespiStrip [13], clinical RT-qPCR [2]). A viral titre at or above the indicated "infectious" line (red) has previously been determined in a virological assessment study of hospital patients [11].

samples yielding false negative results, gargle and swab specimens showed no statistically significant difference in sample $\mathrm{Ct}(\mathrm{P}=0.89$, Mann-Whitney test $)$ or $\mathrm{Ct}$ value distribution $\left(\mathrm{P}_{\text {gargle }}=0.27, \mathrm{P}_{\text {swab }}=\right.$ 0.17 , Kolmogorov-Smirnov test) (Supplementary Figure S1B). Direct RT-qPCR detected SARS$\mathrm{CoV}-2$ in four specimens defined as 'negative' by the diagnostic RT-qPCR assay (Figure 1B). The estimated viral loads of these samples were at the limit of detection by diagnostic RT-qPCR ( $\mathrm{Ct}$ above 38 , less than $\sim 5$ copies per reaction). Given the otherwise high specificity of the direct RTPCR method (98.2\% negative predictive agreement for 223 samples; Figure 1H), we suspect minor cross-contamination from positive samples as the likely cause (e.g. three out of the four samples were adjacent to SARS-CoV-2 positive sample wells).

When using real-time qPCR instruments, the direct RT-qPCR assay is quantitative in nature (Figure 1B). For a simple virus-positive or negative classification, however, an end-point measurement using a standard laboratory PCR machine and a simple illumination device would be sufficient. To test this, we performed end-point fluorescence measurements of RT-qPCR reactions that were also monitored in real-time. This revealed a clear quantitative difference in relative fluorescence units (RFU) between RT-qPCRpositive and -negative samples $(\mathrm{P}<0.0001$, MannWhitney test) (Figure 1C, D). Primary samples with diagnostic $\mathrm{Ct}$ values below or equal to 35 
medRxiv preprint doi: https://doi.org/10.1101/2021.01.19.21250079; this version posted January 20, 2021. The copyright holder for this preprint (which was not certified by peer review) is the author/funder, who has granted medRxiv a license to display the preprint in

It is made available under a CC-BY-NC-ND 4.0 International license .

(more than $\sim 30$ viral copies per reaction) displayed the strongest signal intensity $\left(\mathrm{RFU}_{\max }=5590\right)$, and even weakly positive samples with $\mathrm{Ct}$ values above 37 (less than $\sim 5$ copies per reaction) displayed RFU values greater than the maximum measured for any of the 240 negative samples (Figure 1C, D). Endpoint RT-PCR therefore allows a robust, automated yes/no classification based on comeasured positive and negative control reactions. The strong fluorescent signal is visible in PCR plates or strips when using a standard blue-light transilluminator or a simple blue light LED lamp (Figure 1E, Supplementary Figure S1C), and images can be captured with a standard smartphone camera. We observed $100 \%$ concordance between machine-read (RT-qPCR cycler or plate reader) and visible fluorescence (Figure 1E, Supplementary Figure S1C). For an automated, rapid classification of the assay, fluorescent images can be converted into signal intensities using the FIJI6 plugin ReadPlate (Supplementary Figure S1D).

\section{RT-LAMP}

Isothermal, loop-mediated amplification after reverse-transcription (RT-LAMP) is a powerful nucleic acid amplification method [7] that requires minimal equipment (in its simplest form, a water bath at $62-65^{\circ} \mathrm{C}$ [1]; Figure 1A, Supplementary Figure S2A, B). RT-LAMP based DNA amplification is rapid ( $<30$ minutes) and, due to the large amount of generated DNA products, allows the use of a colorimetric and/or fluorescence readout [8]. Instead of the $\mathrm{pH}$ dependent dye Phenol Red commonly used in RTLAMP assays, we chose the metal-indicator HNB [9] as it is compatible with the QuickExtract buffer and all commonly used specimen types (like swabs, gargle samples, saliva, sputum) and media (VTM, saline, HBSS) [1,4]. To simultaneously detect fluorescence, we used the SYTO-9 dye (detailed LAMP protocol available at https:// www.rtlamp.org/). From the 384 patient samples, RT-LAMP targeting the SARS-CoV-2 ORF1ab gene [10] detected 94 out of the 161 RT-qPCR positive samples $(58 \%)$ while maintaining a $100 \%$ negative predictive agreement rate with no false positive results among the 223 specimens that were determine 'negative' by diagnostic RT-qPCR (Figure 1F, H). Concordance between colorimetric results $($ sky-blue $=$ positive, purple $=$ negative) and fluorescence intensity (LAMP end-point RFU) was $100 \%$, demonstrating the reliability in detecting positive specimens based on colorimetric signal alone (Figure 1F, Supplementary Figure S3). The assay sensitivity for samples with a diagnostic RTqPCR Ct value below or equal to 30 was $96.1 \%$ (74/77), 44.8\% for $\mathrm{Ct}$ values between 30 to 35 $(13 / 29)$, and $12.7 \%$ for weakly positive samples with $\mathrm{Ct}$ values above or equal to 35 (7/55) (Figure
1F, H). The mean time-to-threshold (time until fluorescent signal reached a threshold value) was $\sim 15$ minutes (range from 9.9 to 23.3 minutes) (Supplementary Figure S2C). Reactions displaying an intermediate colour had time to threshold values of more than 20 minutes (Figure $1 \mathrm{~F}$, Supplementary Figure S2C), indicating that for lower viral loads (RT-qPCR Ct values above 33) fluorescence is the more robust readout. Thus, RTLAMP is a very fast, simple and versatile assay that has a sensitivity sufficient to identify SARSCoV-2 in samples from infectious individuals [11] (Figure 1I).

\section{Bead-LAMP}

To increase the sensitivity of RT-LAMP, we developed bead-enriched RT-LAMP (in short, bead-LAMP), which uses a 15-minute, magnetic bead based enrichment step to capture RNA from up to $100 \mu \mathrm{l}$ inactivated patient samples (Figure 1A, Supplementary Figure S2B) [1]. RNA elution in bead-LAMP is done directly with the RT-LAMP reaction mix, increasing speed and allowing for maximum RNA enrichment. As bead-enrichment removes sample buffer and matrix components, it is compatible with Phenol Red-based colorimetric detection ( pink $=$ negative; yellow $=$ positive) (Figure 1G, Supplementary Figure S2B, Supplementary Figure S3; for detailed bead-LAMP protocols visit https://www.rtlamp.org/). BeadLAMP can be performed manually as well as on the commonly used, fully automated Kingfisher Flex purification system, which reduces the amount of valuable reaction consumables such as pipette tips. Bead-LAMP detected 115 out of 161 RT-qPCR positive samples (71.4\%) (Figure 1G). As expected, bead-LAMP improved assay sensitivity, detecting $83 \%(30 / 36)$ of samples with diagnostic $\mathrm{Ct}$ values between 30 and $35,31 \%$ for Ct values above 35 (17/55) and even 19.5\% (8/41) of samples with $\mathrm{Ct}$ values above 37 (Figure 1G, H). In comparison, direct RT-LAMP detected only 1 out of 41 samples in the $\mathrm{Ct}$ range above 37 (Figure 1F, H). Out of 223 specimens that yielded negative results by RT-qPCR, three specimens $(1.3 \%)$ showed positive results when tested by bead-LAMP (Figure 1G). None of these three samples were positive in direct RT-qPCR or RTLAMP, suggesting that they were in fact incorrect positive results of the bead-LAMP assay. We suspect that minor cross-contaminations during sample handling are the underlying cause of the false positive results. Compared to the manual bead-LAMP protocol, the automated KingFisher system improved the overall performance of beadLAMP despite using lower sample input volume per sample $(60 \mu 1$ versus $100 \mu \mathrm{l})$. We measured a subset of samples $(n=288)$ in parallel using manual and automated bead-LAMP and observed 
medRxiv preprint doi: https://doi.org/10.1101/2021.01.19.21250079; this version posted January 20, 2021. The copyright holder for this preprint (which was not certified by peer review) is the author/funder, who has granted medRxiv a license to display the preprint in

It is made available under a CC-BY-NC-ND 4.0 International license .

higher detection rates in the fully automated KingFisher version (Supplementary Figure S2D, S3). As for RT-LAMP, no difference in sensitivity was observed for bead-LAMP between gargle and swab samples (Supplementary Figure S2E), demonstrating compatibility with diverse input samples. Taken together, bead-LAMP is an attractive solution for applications where increased assay sensitivity is required, such as for pooled testing [1].

Our comparative study highlights three laboratory-developed SARS-CoV-2 tests that are cheap (reagent costs $\sim 1$ USD for RT-qPCR and RTLAMP, 1.2 USD for bead-LAMP), rapid (45 - 80 min total test time), simple, and that circumvent supply chain bottlenecks. The three assays hold the potential to greatly expand the availability of affordable testing strategies anywhere in the world. Our data demonstrate that direct RT-PCR, RTLAMP and bead-LAMP are fully compatible with crude sample lysates without measurable reaction inhibition. In line with previous studies [5,10,12], this strongly supports the validity of extraction-free nucleic acid diagnostics. All three assays are inherently scalable and have a sensitivity that exceeds the required threshold to detect infectious individuals, which only the best commercial rapid Antigen point-of-care tests achieve [13] (Figure 1I). All three assays are compatible with various input types such as swabs or gargle, the latter offering a simple, non-invasive way of selfcollecting the specimen without the need of trained, specialized personell. Finally, all three of the rapid assays highlighted here take advantage of the dUTP/UDG system [14-16], which we used throughout this study in order to minimize technical false-positive results due to carry-over contamination with prior PCR or LAMP amplicons.

Depending on the available equipment and desired assay sensitivity, our nucleic acid amplification assays provide an effective alternative to diagnostic RT-qPCR testing, where dependencies on commercial testing platforms and reagent supply shortages could lead to unused testing capacities. Laboratories already performing RT-qPCR or regular PCRs could implement direct RT-qPCR or end-point RT-PCR, while our endpoint RT-PCR and colorimetric RT-LAMP protocols provide powerful, simple testing methods to greatly increase the testing capacity particularly in settings where qPCR detection instruments are unavailable. For settings in which speed and simplicity matters, colorimetric RT-LAMP is the most powerful method. Furthermore, the sensitivity of RT-PCR for pooled tests, and the speed of RTLAMP for de-pooling could be combined to massively scale up testing in cases of low viral prevalence in the population [17]. In this, our rapid and cost-effective methods could enable any country to establish population-wide testing strategies, which would be highly effective in limiting the spread of contagious viruses such as SARS-CoV-2 [18,19].

\section{ACKNOWLEDGMENTS}

This work would not have been possible without the enthusiastic support of the IMBA and IMP research institutes, as well as the many volunteers and partners of the VCDI, who came together to help and collaborate under the exceptional circumstances of the Covid-19 pandemic. Special thanks go to H. Isemann for his administrative and overall support, as well as to the Covid-19 NGS team (R. Yelagandula, L. Cochella and Uli Elling) for discussions and experimental advice. We thank the Pauli and Brennecke groups for bearing with us and sharing lab space. We thank Nathan Tanner (NEB) for valuable discussions and sharing important information on LAMP technology. We are grateful to the Covid Testing Scaleup SLACK channel for openly sharing and exchanging information and the Covid-19 diagnostics team in Feng Zhang's lab for discussions.

\section{AUTHOR CONTRIBUTIONS}

MJK and MM designed, performed and analyzed all experiments. MJK, MM, JJR, JSchnabl and DH developed LAMP and directPCR assays. RH established the KingFisher protocol. FA, AI, PH and JSchaeffer coordinated patient samples and provided clinical RT-qPCR measurements. MF, RFP, JZ and MPSD provided and helped with patient samples for method development. JZ acquired project funding. The VCDI supported Covid-19 testing initiatives at the Vienna BioCenter. MJK, AP and JB conceived the project. AP and JB supervised the project. MJK, $\mathrm{MM}, \mathrm{AP}$ and JB wrote the paper with input from all authors.

\section{FUNDING}

MJK was supported by the Vienna Science and Technology Fund (WWTF; project COV20-031; to JZ). The LAMP project development received generous funding from the MILA foundation. Research in the Pauli lab is supported by the Austrian Science Fund (START Projekt Y 1031B28, SFB 'RNA-Deco' $F$ 80) and EMBO-YIP; research in the Brennecke lab is supported by the European Research Council (ERC-2015-CoG 682181). The IMP receives institutional funding 
medRxiv preprint doi: https://doi.org/10.1101/2021.01.19.21250079; this version posted January 20, 2021. The copyright holder for this preprint (which was not certified by peer review) is the author/funder, who has granted medRxiv a license to display the preprint in

It is made available under a CC-BY-NC-ND 4.0 International license .

from Boehringer Ingelheim and the Austrian Research Promotion Agency (Headquarter grant FFG-852936); IMBA is supported by the Austrian Academy of Sciences. Justine $\mathrm{S}$ was supported by a grant from the European Public Health Microbiology Training Programme (EUPHEM), European Centre for Disease Prevention and Control (specific grant agreement number 1 ECD. 7550 implementing ECDC/GRANT/2017/003).

\section{DECLARATION OF INTERESTS}

The authors declare no competing interests.

\section{REFERENCES}

1 Kellner, M. J. et al. Scalable, rapid and highly sensitive isothermal detection of SARS-CoV-2 for laboratory and home testing. bioRxiv, 2020.2006.2023.166397, doi:10.1101/2020.06.23.166397 (2020).

2 Corman, V. M. et al. Detection of 2019 novel coronavirus $(2019-\mathrm{nCoV})$ by realtime RT-PCR. Euro Surveill 25, 2000045, d o i : $10.2807 / 1560-7917$. E S . 2020.25.3.2000045 (2020).

3 Ladha, A., Joung, J., Abudayyeh, O., Gootenberg, J. \& Zhang, F. A 5-min RNA preparation method for COVID-19 detection with RT-qPCR. medRxiv, 2020.2005 .2007 .20055947 , doi: 10.1101/2020.05.07.20055947 (2020).

4 Yelagandula, R. et al. SARSeq, a robust and highly multiplexed NGS assay for parallel detection of SARS-CoV2 and other respiratory infections. medRxiv, 2020.2010 .2028 .20217778 , doi: 10.1101/2020.10.28.20217778 (2020).

5 Smyrlaki, I. et al. Massive and rapid COVID-19 testing is feasible by extraction-free SARS-CoV-2 RT-PCR. Nature communications 11, 4812, doi: 10.1038/s41467-020-18611-5 (2020).

Angelani, C. R. et al. A metabolic control analysis approach to introduce the study of systems in biochemistry: the glycolytic pathway in the red blood cell. Biochemistry and Molecular Biology Education 46, 502-515, doi:https://doi.org/ 10.1002/bmb.21139 (2018).

Notomi, T. et al. Loop-mediated isothermal amplification of DNA. Nucleic Acids Res 28, e63-e63, doi:10.1093/nar/28.12.e63 (2000).
Tanner, N. A., Zhang, Y. \& Evans, T. C. Visual detection of isothermal nucleic acid amplification using $\mathrm{pH}$-sensitive dyes. BioTechniques 58, 59-68, doi: 10.2144/000114253 (2015).

Goto, M., Honda, E., Ogura, A., Nomoto, A. \& Hanaki, K.-I. Colorimetric detection of loop-mediated isothermal amplification reaction by using hydroxy naphthol blue. BioTechniques 46, 167-172, doi: 10.2144/000113072 (2009).

Rabe, B. A. \& Cepko, C. SARS-CoV-2 detection using isothermal amplification and a rapid, inexpensive protocol for sample inactivation and purification. Proceedings of the National Academy of Sciences 117, 24450, doi:10.1073/pnas. 2011221117 (2020).

1 Wölfel, R. et al. Virological assessment of hospitalized patients with COVID-2019. Nature 581, 465-469, doi:10.1038/ s41586-020-2196-x (2020).

Dao Thi, V. L. et al. A colorimetric RTLAMP assay and LAMP-sequencing for detecting SARS-CoV-2 RNA in clinical samples. Science Translational Medicine 12 , e a b c 7075 , doi:10.1126/ scitranslmed.abc7075 (2020).

Corman, V. M. et al. Comparison of seven commercial SARS-CoV-2 rapid Point-ofCare Antigen tests. medRxiv, 2020.2011 .2012 .20230292 , doi: 10.1101/2020.11.12.20230292 (2020).

Longo, M. C., Berninger, M. S. \& Hartley, J. L. Use of uracil DNA glycosylase to control carry-over contamination in polymerase chain reactions. Gene 93, $125-128, \quad$ d o i : 10.1016/0378-1119(90)90145-h (1990).

Hsieh, K., Mage, P. L., Csordas, A. T., Eisenstein, M. \& Tom Soh, H. Simultaneous elimination of carryover contamination and detection of DNA with uracil-DNA-glycosylase-supplemented loop-mediated isothermal amplification (UDG-LAMP). Chemical Communications 50, 3747-3749, doi:10.1039/C4CC00540F (2014).

Robinson-McCarthy, L. R. et al. Anomalous COVID-19 tests hinder researchers. Science (New York, N.Y.) 371, 244, doi:10.1126/science.abf8873 (2021).

17 Mutesa, L. et al. A pooled testing strategy for identifying SARS-CoV-2 at low 
medRxiv preprint doi: https://doi.org/10.1101/2021.01.19.21250079; this version posted January 20, 2021. The copyright holder for this preprint (which was not certified by peer review) is the author/funder, who has granted medRxiv a license to display the preprint in It is made available under a CC-BY-NC-ND 4.0 International license .

prevalence. Nature, doi:10.1038/ s41586-020-2885-5 (2020).

Larremore, D. B. et al. Test sensitivity is secondary to frequency and turnaround time for COVID-19 screening. Science Advances 7, eabd5393, doi:10.1126/ sciadv.abd5393 (2021).

Grassly, N. C. et al. Comparison of molecular testing strategies for COVID-19 control: a mathematical modelling study. The Lancet Infectious Diseases 20, $1381-1389$, doi:10.1016/ S1473-3099(20)30630-7 (2020).

Toussaint, J. F., Sailleau, C., Breard, E., Zientara, S. \& De Clercq, K. Bluetongue virus detection by two real-time RT-qPCRs targeting two different genomic segments. Journal of virological methods 140 , 115-123, doi:10.1016/j.jviromet. 2006.11.007 (2007).

Zhang, Y. et al. Enhancing Colorimetric LAMP Amplification Speed and Sensitivity with Guanidine Chloride. bioRxiv, 2020.2006.2003.132894, doi: 10.1101/2020.06.03.132894 (2020).

\section{MATERIALS AND METHODS}

\section{Clinical sample collection}

Patient samples (oro/nasopharyngeal swabs and gargle) were obtained as part of a clinical performance study approved by the local Ethics Committee of the City of Vienna (\#EK 20-292-1120). Oro/Nasopharyngeal swabs were collected in $3 \mathrm{ml}$ Viral Transport Medium (VTM) or $0.9 \% \mathrm{NaCl}$ solution (saline). Gargle samples were collected from patients by letting individuals gargle for 1 minute with $5 \mathrm{ml}$ of Hank's Balanced Salt Solution (HBSS) or $0.9 \%$ saline solution. Informed consent was obtained from all patients.

\section{RNA extraction and clinical RT-qPCR}

RNA was extracted from $200 \mu 1$ of NP and OP swab supernatants using a commercial kit (BioExtract ${ }^{\circledR}$ SuperBall ${ }^{\circledR}$, BioSellal, France) and the KingFisher ${ }^{\mathrm{TM}}$ Flex Purification System (Thermo Fisher Scientific, USA). Negative extraction controls (nuclease-free water) were prepared alongside clinical samples to monitor for potential cross-contamination. Detection of SARSCoV-2 RNA was performed using a commercial primer/probe mix (LightMix ${ }^{\circledR}$ Modular SARS and
Wuhan CoV E-gene; TIB Molbiol, Germany) and SuperScript ${ }^{\mathrm{TM}}$ III Platinum ${ }^{\circledR}$ One-Step Quantitative RT-PCR System with ROX (Thermo Fisher Scientific, USA) on the ABI7500Fast system (Thermo Fisher Scientific, USA). Assays were performed as in duplicate as real-time RTPCR reactions, also targeting $\beta$-actin mRNA as extraction control [20]. Nuclease-free water and a synthetic RNA control provided with the primer/ probe mix were included as respective notemplate-control (NTC) and positive control (PC). A CT-value of $>40$ was considered a negative result.

\section{Crude sample inactivation using QuickExtract DNA solution}

$120 \mu 1$ of naso/oro-pharyngeal swab or gargle sample was mixed 1:1 with QuickExtract ${ }^{\mathrm{TM}}$ DNA Extraction Solution (Lucigen) and heat inactivated for 5 minutes at $95^{\circ} \mathrm{C}$. Samples were then stored on ice until further use or frozen at $-80^{\circ} \mathrm{C}$.

\section{Direct RT-PCR}

For detecting the viral N-gene via RT-qPCR, 1-step RT-qPCR was performed using the Luna Universal One-Step RT-qPCR Kit (NEB), $1.5 \mu 1$ of reference primer/probe sets CDC-N1 (IDT 10006713), $0.4 \mu 1$ of Antarctic Thermolabile UDG (NEB), and $2 \mu 1$ of QuickExtract inactivated crude sample lysate per $20 \mu 1$ reaction. Reactions were run at $55^{\circ} \mathrm{C}$ for 10 minutes, $95^{\circ} \mathrm{C}$ for 1 minute, followed by 45 cycles of $95^{\circ} \mathrm{C}$ for 10 seconds and $55^{\circ} \mathrm{C}$ for 30 seconds in a BioRad CFX qPCR cycler. End-point measurements were taken on the BioRad CFX qPCR cycler after 45 cycles of amplification and plotted without baseline subtraction. Alternatively, PCR plates were placed on a LED Blue-light Transilluminator (Safe Imager 2.0, Thermofisher) and photographed using a regular smartphone camera (iPhone XS). The Fiji plugin ReadPlate was used to convert the smartphone image into numerical values according to the plugin's manual instructions.

\section{RT-LAMP}

For detailed, up-to-date protocols on the RT-LAMP assay visit https://www.rtlamp.org/get-started/rtlamp-commercial/. In brief, RT-LAMP reactions were set up by mixing $10 \mu \mathrm{l}$ of the $2 \mathrm{X}$ NEB WarmStart ${ }^{\circledR}$ RT-LAMP Master Mix (1x final, 2x stock) with $2 \mu \mathrm{l}$ of 10x ORF1a-HMS primer solution [10] (1x final equals $1.6 \mu \mathrm{M}$ of FIP, 1.6 $\mu \mathrm{M}$ of BIP, $0.4 \mu \mathrm{M}$ of LB, $0.4 \mu \mathrm{M}$ of LF, $0.2 \mu \mathrm{M}$ of F3, $0.3 \mu \mathrm{M}$ of B3), $0.4 \mu \mathrm{l}$ of $100 \mu \mathrm{M}$ SYTO-9 dye (Thermofisher, made from $5 \mathrm{mM}$ Stock in DMSO), $0.4 \mu 1$ of NEB Antarctic thermolabile UDG, $0.14 \mu 1$ of $100 \mathrm{mM}$ dUTP solution (NEB, $0.7 \mathrm{mM}$ final dUTP added), $0.14 \mu \mathrm{l}$ of $100 \mathrm{mM}$ MgSO4 (NEB, $0.7 \mathrm{mM}$ added), $0.8 \mu \mathrm{l}$ of $3 \mathrm{mM}$ 
medRxiv preprint doi: https://doi.org/10.1101/2021.01.19.21250079; this version posted January 20, 2021. The copyright holder for this preprint (which was not certified by peer review) is the author/funder, who has granted medRxiv a license to display the preprint in

It is made available under a CC-BY-NC-ND 4.0 International license .

hydroxynapthol blue (120 $\mu \mathrm{M}$ final, stock solution made from HNB powder (Hach) in nuclease-free water and filtered through $0.22 \mu \mathrm{m}$ filter), $2 \mu \mathrm{l}$ of QuickExtract inactivated crude sample lysate and nuclease-free water to a final volume of $20 \mu \mathrm{l}$. Reactions were run at $63^{\circ} \mathrm{C}$ for 35 cycles $(1$ minute cycle length) in a BioRad CFX Connect qPCR cycler with SYBR readings after every cycle. Colorimetric signal was read out after reaction completion using a simple smartphone camera. Reactions with sky blue color were scored as positive, purple color as negative and everything between as intermediate. A separate classification was done to compare results using a color conversion tool (colorimetry.net) which rotates the color space by $180^{\circ}$ to invert reaction colors into orange (positive) or yellow (negative).

\section{Bead-LAMP}

For detailed, up-to-date protocols on the beadLAMP assay visit https://www.rtlamp.org/getstarted/bead-lamp-commercial/. In brief, for bead enrichment, $60 \mu \mathrm{l}$ or $100 \mu \mathrm{l}$ of QuickExtract inactivated crude lysate was mixed with $0.6 \mathrm{x}$ of magnetic beads (1:5 dilution of Agencourt RNAClean XP in $2.5 \mathrm{M} \mathrm{NaCl}, 10 \mathrm{mM}$ Tris-HCl $\mathrm{pH} 8.0,20 \%$ (w/v) PEG 8000, 0.05\% Tween 20, 5 mM NaN3) and either manually or automatically processed. For manual bead-LAMP, bead-sample mixtures were incubated for 5 minutes at room temperature followed by bead capture on a magnetic rack (Alpaqua 96S Super Magnet) for 5 minutes. The liquid was removed and beads were washed twice with $85 \%$ ethanol for 30 seconds. The beads were air dried for 5 minutes and then eluted directly in $20 \mu \mathrm{l}$ colorimetric LAMP reaction mix containing $10 \mu 1$ of $2 x$ NEB WarmStart ${ }^{\circledR}$ Colorimetric LAMP Master Mix with UDG (1x final), $2 \mu 1$ of 10x ORF1a-HMS [10] and $2 \mu 1$ of NEB E1 primer solution [21] (1x final equals $1.6 \mu \mathrm{M}$ of FIP, $1.6 \mu \mathrm{M}$ of BIP, $0.4 \mu \mathrm{M}$ of $\mathrm{LB}, 0.4 \mu \mathrm{M}$ of LF, $0.2 \mu \mathrm{M}$ of F3, $0.3 \mu \mathrm{M}$ of B3), $0.4 \mu 1$ of $2 \mathrm{M} \mathrm{GuHCl}(40 \mathrm{mM}$ final, $2 \mathrm{M}$ Stock made from $\mathrm{pH} 8.5$ buffered solution in water (Sigma G7294)), $0.4 \mu 1$ of $100 \mu \mathrm{M}$ SYTO-9 dye (ThermoFisher, made from $5 \mathrm{mM}$ Stock in DMSO) and nuclease-free water to a final volume of $20 \mu \mathrm{l}$. For automated bead-LAMP, we established a custom protocol for the KingFisher ${ }^{\mathrm{TM}}$ Flex Purification System: The protocol was designed for a 96-well PCR magnetic head and maximum 100 $\mu \mathrm{l}$ of total sample volume. After mixing $60 \mu \mathrm{l}$ of crude lysate with $40 \mu 1$ of magnetic beads (1:5 dilution of Agencourt RNAClean XP in $2.5 \mathrm{M}$ $\mathrm{NaCl}, 10 \mathrm{mM}$ Tris- $\mathrm{HCl} \mathrm{pH}$ 8.0, 20\% (w/v) PEG $8000,0.05 \%$ Tween $20,5 \mathrm{mM} \mathrm{NaN} 3$ ), the sample plate was placed into the KingFisher system. The protocol was initiated by mixing for 5 minutes at medium speed. Next, beads were collected through
5 iterations of 30 seconds each. Then beads were washed for 15 seconds in a wash plate containing $85 \%$ EtOH. For this, a bead-release step of 15 seconds was done in the beginning of the wash step, followed by collecting the beads three times for 5 seconds. Beads were then air-dried for 3 minute and released into the bead-LAMP reaction mixture for 1 minute at fast speed. The protocol is available upon request.

Both manual and automated KingFisher beadLAMP reactions were run at $63^{\circ} \mathrm{C}$ for 25 cycles $(1$ minute cycle length) in a BioRad CFX Connect qPCR cycler with SYBR readings after every cycle. Colorimetric signal was read out after reaction completion using a simple smartphone camera. Reactions with yellow color were scored as positive, pink color as negative and everything between as intermediate.

\section{LAMP primer sequences}

ORF1a-HMS:

ORF1a-HMS F3

CGGTGGACAAATTGTCAC

ORF1a-HMS_B3:

CTTCTCTGG̈ATTTAACACACTT

ORF1a-HMS LF:

TTACAAGCTTAAAGAATGTCTGAACACT

ORF1a-HMS LB:

TTGAATTTAGGTGAAACATTTGTCACG

ORF1a-HMS_FIP:

TCAGCACACAAAGCCAAAAATTTATCTGTG

CAAAGGAAATTAAGGAG

ORF1a-HMS BIP:

TATTGGTGGAGCTAAACTTAAAGCCCTGTAC AATCCCTTTGAGTG

NEB-E1:

NEB-E1_F3:

TGAGTĀCGAACTTATGTACTCAT

NEB-E1_B3:

TTCAGĀTTTTTAACACGAGAGT

NEB-E1 FIP:

ACCACGAAAGCAAGAAAAAGAAGTTCGTT

TCGGAAGAGACAG

NEB-E1 BIP:

TTGCTÄGTTACACTAGCCATCCTTAGGTTTT

ACAAGACTCACGT

NEB-E1 LB:

GCGCTT̄CGATTGTGTGCGT

NEB-E1 LF:

CGCTATTAACTATTAACG 
medRxiv preprint doi: https://doi.org/10.1101/2021.01.19.21250079; this version posted January 20, 2021. The copyright holder for this preprint (which was not certified by peer review) is the author/funder, who has granted medRxiv a license to display the preprint in perpetuity.

It is made available under a CC-BY-NC-ND 4.0 International license

\section{SUPPLEMENTARY FIGURES}

A

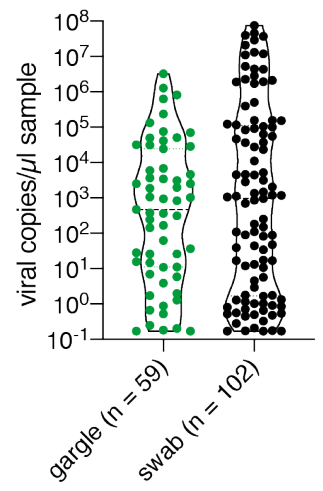

B

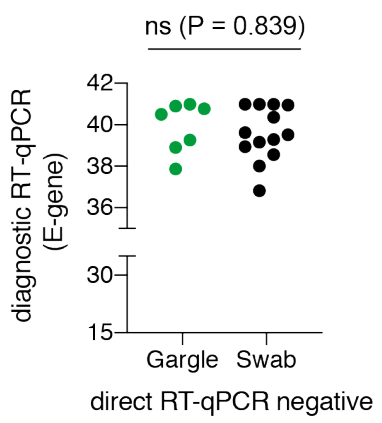

C
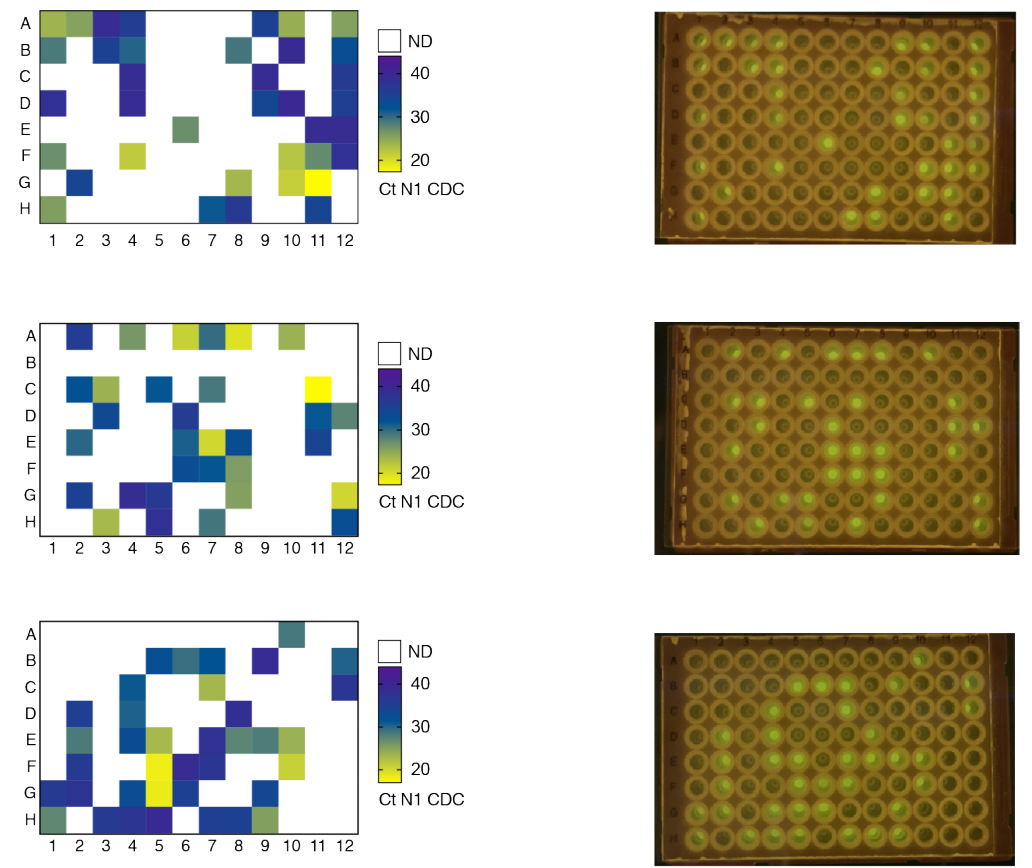

D
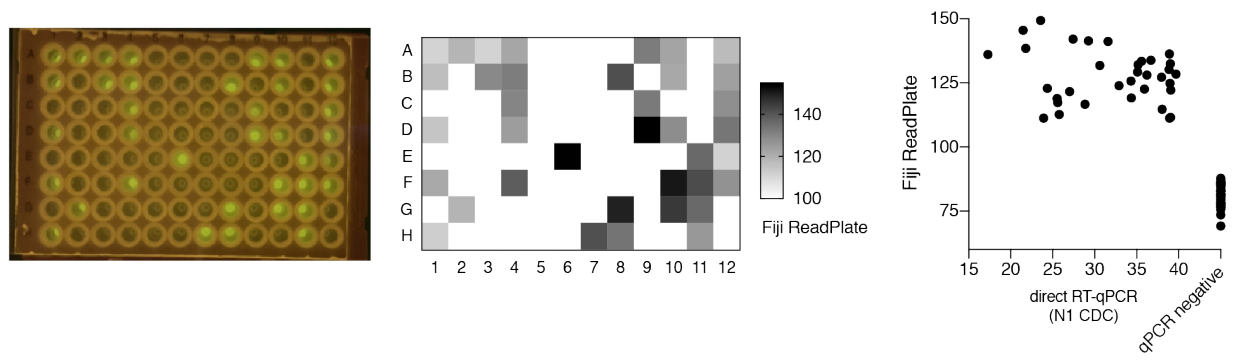

Figure S1: Real-time and end-point fluorescence direct RT-PCR

A. Violin plot showing estimated SARS-CoV-2 RNA copies per clinical sample (naso/oropharyngeal swab or gargle). A standard curve was used to convert $\mathrm{Ct}$ values into viral copies per reaction and projected to the total sample volume ( $3 \mathrm{ml}$ for naso/oropharyngeal swab, $5 \mathrm{ml}$ for gargle).

B. Comparison of diagnostic RT-qPCR Ct values that were not detected by direct RT-qPCR by sample type (gargle versus naso/oropharyngeal swab). No significant (ns) difference was observed between the two groups $(\mathrm{P}=0.839$, Mann-Whitney test).

C. Heatmap showing measured direct RT-qPCR Ct values for three different sample plates (left) and the corresponding end-point fluorescence smartphone images taken on a standard LED blue-light transilluminator (right).

D. Semi-automated classification of end-point fluorescence smartphone images by digitalisation of the raw fluorescence images. The smartphone image (left) is analysed using the Fiji ReadPlate plugin, which converts fluorescence intensities into numerical values. The numerical values are shown as heatmap in plate-format (middle) or scatterplot with the corresponding direct RT-qPCR Ct values (right). 
medRxiv preprint doi: https://doi.org/10.1101/2021.01.19.21250079; this version posted January 20, 2021. The copyright holder for this preprint (which was not certified by peer review) is the author/funder, who has granted medRxiv a license to display the preprint in

It is made available under a CC-BY-NC-ND 4.0 International license .

A

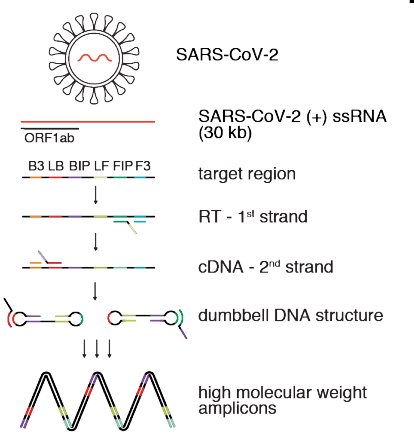

B

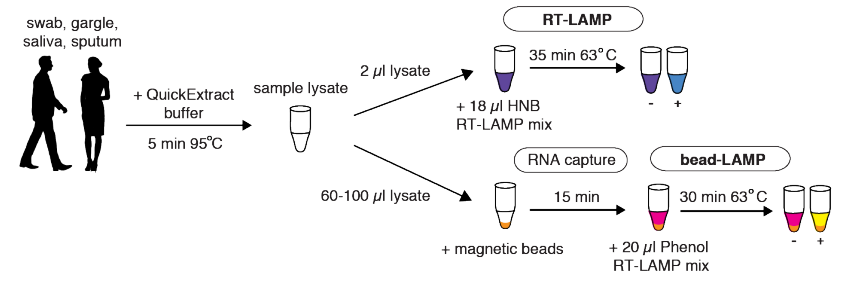

C

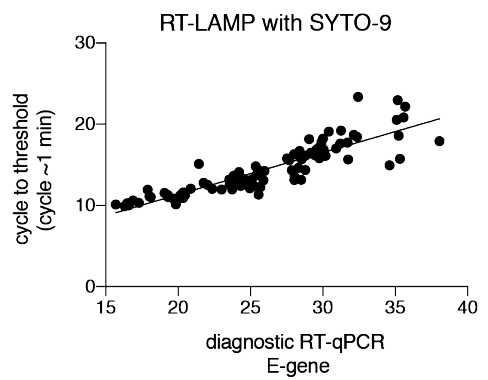

D
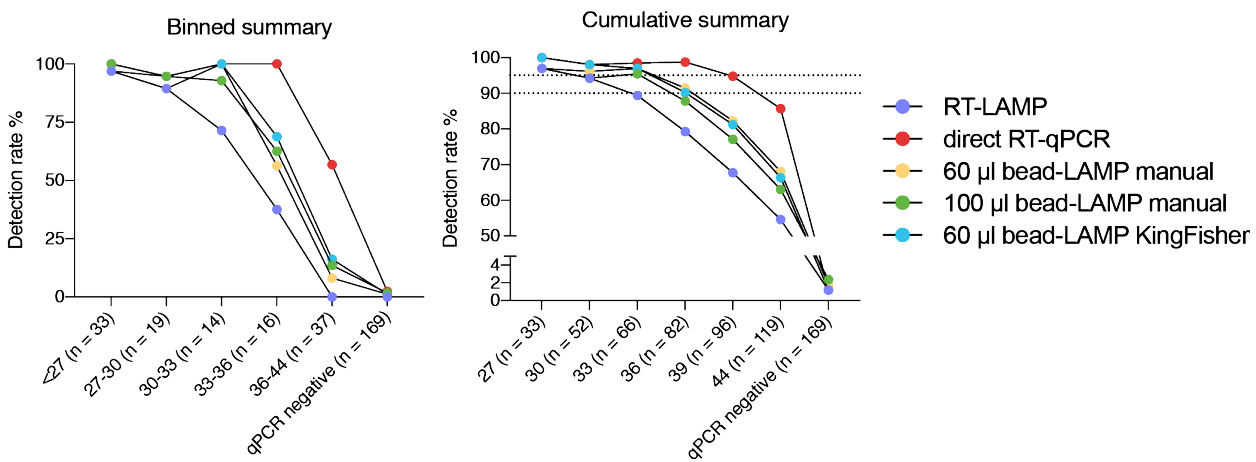

E
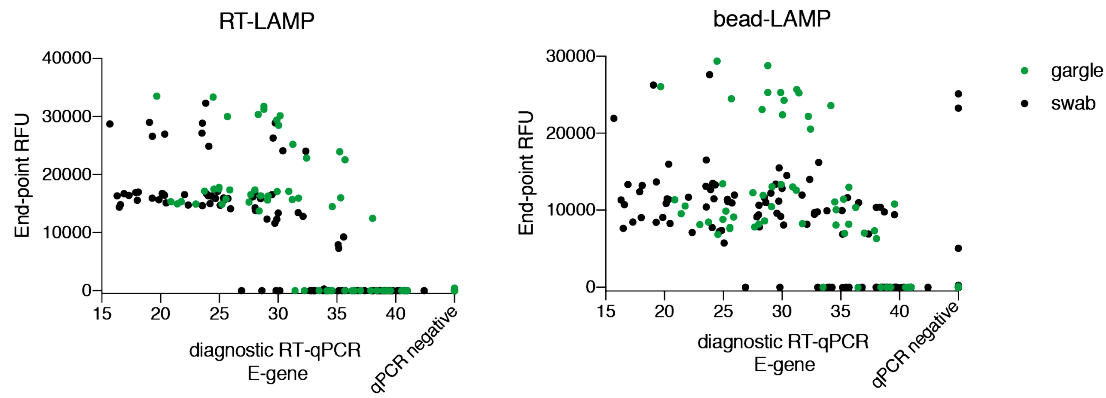

Figure S2: RT-LAMP and bead-LAMP

A. Schematic illustrating the reaction principle of reverse transcription loop-mediated amplification (RT-LAMP) of SARS-CoV-2 RNA and the RNA region targeted in this study (Orflab). The target region is recognized by a defined set of primers (B3, LB, BIP, LF, FIP, F3). The RNA template (red) is reverse transcribed and displaced after first-strand synthesis; the outer primer binding sites are added in the subsequent amplification step. The resulting dumbbell DNA structure acts as template for further rounds of amplification, ultimately leading to high molecular weight amplicons.

B. Schematic illustrating the workflow for the clinical assessment of RT-LAMP using HNB colorimetric read-out (top) or bead-LAMP using Phenol-red colorimetric read-out (bottom). Bead-LAMP includes an upstream step, in which RNA is captured from crude lysate using magnetic beads, followed by elution by the RT-LAMP reaction mixture [1].

C. Scatterplot comparing RT-LAMP reaction times to direct RT-qPCR Ct values for each sample. The RT-LAMP reaction time was obtained by real-time fluorescence RT-LAMP, using SYTO-9 as fluorescent dye, and corresponds to the time at which the fluorescence RT-LAMP signal crosses the signal threshold.

D. Determined binned (left) and cumulative (right) assay sensitivity of RT-LAMP (blue), bead-LAMP (yellow) and direct RT-PCR on 288 individual clinical samples. For bead-LAMP, both manual and automated (KingFisher) protocol performances using different amounts of sample input are shown.

E. Scatterplots comparing real-time diagnostic RT-qPCR Ct values (x-axis) to RT-LAMP relative fluorescence units (y-axis). The color indicates the sample type (naso/oropharyngeal swabs or gargle). RT-LAMP is shown on the left, bead-LAMP is shown on the right. 
medRxiv preprint doi: https://doi.org/10.1101/2021.01.19.21250079; this version posted January 20, 2021. The copyright holder for this preprint (which was not certified by peer review) is the author/funder, who has granted medRxiv a license to display the preprint in perpetuity.

It is made available under a CC-BY-NC-ND 4.0 International license .

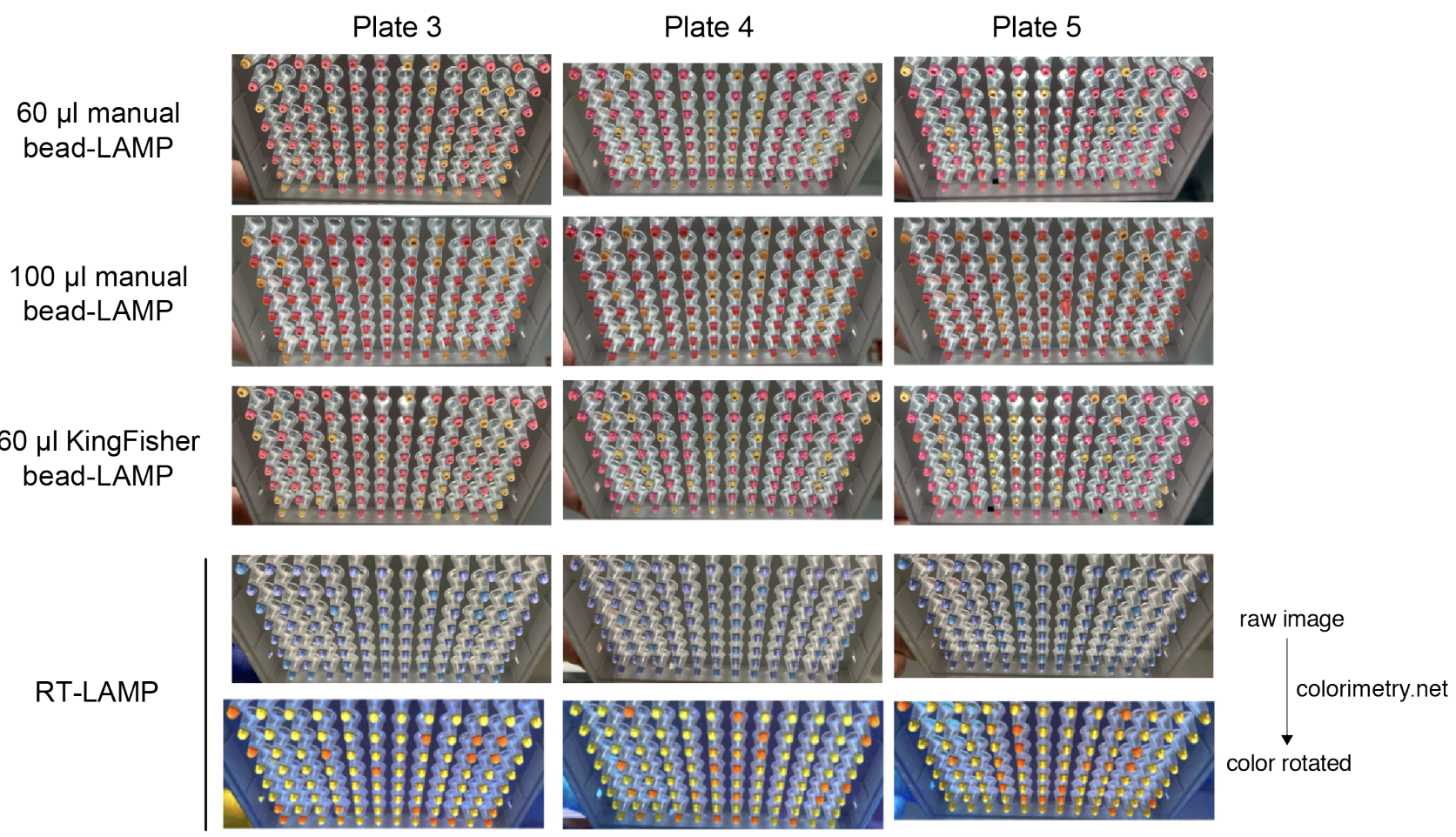

Figure S3: Colorimetric read-out of RT-LAMP and bead-LAMP

Shown are images from bead-LAMP and RT-LAMP after reaction completion for three independent sample plates (columns). For bead-LAMP, plate images for different lysate amounts as well as the performed protocol (manual versus automated KingFisher) are shown. To facilitate sample classification of colorimetric RT-LAMP reactions using the HNB dye, color converted images (www.colorimetry.net) are depicted underneath the original images obtained for those reactions. 